\title{
Nanocrystalline Titania Coated Metakaolin and Rice Hull Ash Based Geopolymer Spheres for Photocatalytic Degradation of Dyes in Wastewater
}

\author{
PATRICIA ISABEL BRAVO', EIZA SHIMIZU', ROY ALVIN MALENAB' ${ }^{2}$, APRIL ANNE TIGUE², \\ KIMMIE MAE DELA CERNA², JOSE ISAGANI JANAIRO ${ }^{3,4}$, MICHAEL ANGELO PROMENTILLA ${ }^{2,4}$ \\ and DERRICK ETHELBHERT YU ${ }^{1,4 *}$
}

\begin{abstract}
'Department of Chemistry, De La Salle University, 2401 Taft Avenue, Manila, Philippines. 2Department of Chemical Engineering, De La Salle University, 2401 Taft Avenue, Manila, Philippines.

${ }^{3}$ Department of Biology, De La Salle University, 2401 Taft Avenue, Manila, Philippines. ${ }^{4}$ Materials Science and Nanotechnology Unit, De La Salle University, 2401 Taft Avenue, Manila, Philippines. *Corresponding author E-mail: derrick.yu@ dlsu.edu.ph
\end{abstract}

http://dx.doi.org/10.13005/ojc/350118

Received: January 20, 2019; Accepted: February 05, 2019)

ABSTRACT

Geopolymer spheres made from metakaolin and rice hull ash have exceptional chemical and mechanical stability, making them promising catalyst support matrix for photoactive compounds. In this paper, titania was deposited on geopolymer sphere via horizontal vapor phase growth method, which produced nanotitania crystals embedded on the surface. The titania-coated geopolymer spheres resulted in $90 \%$ dye photodegradation activity that can be used repeatedly thus qualifying the products as sustainable materials for wastewater treatment.

Keywords: Geopolymer, Nanotitania photocatalyst, Photocatalytic degradation, Nanotitania deposition.

\section{INTRODUCTION}

The increasing variety and amount of hazardous compounds produced and discharged by the printing, dyeing, textile and various chemical industries mainly contribute to water pollution. Advanced oxidation processes (AOPs) by generation of reactive oxygen species (ROS) are proven to be most effective in wastewater treatment, due to the high oxidative power of radicals that produce stable, more biodegradable by-products ${ }^{1}$. Among the photocatalysts used in AOPs, titanium dioxide or more commonly known as titania $\left(\mathrm{TiO}_{2}\right)$, is the most efficient and the most widely used photocatalyst for photodegradation of organic and inorganic dyes in wastewaters. It exists in a variety of polymorphs, such as anatase, rutile and brookite, with $\mathrm{Eg}=$ 3.2, 3.0 and $2.2 \mathrm{eV}$, respectively, giving different photocatalytic activities. Aside from the crystal orientation, the photocatalytic activity of titania is also influenced by its particle size and morphology. Reduction of particle size to nanoscale increases

This is an Open Access article licensed under a Creative Commons license: Attribution 4.0 International (CC- BY). Published by Oriental Scientific Publishing Company @ 2018 
its photoactivity due to the added discrete energy levels formed as a result of confinement effects ${ }^{2}$, while extension of surface area from spheres to rods/belts would have lower recombination rate due to increased charge mobility along the longitudinal dimension ${ }^{3}$. Currently, titania is used in wastewater treatment either by suspension or immobilization². However, immobilization of the photocatalyst is more practical and preferred since it allows easy collection and recycling of titania ${ }^{4}$. Several deposition techniques employ glass as the substrate, however, the aim of producing a reusable material is limited by the brittle property of glass. A substitute to glass substrate is geopolymer.

Geopolymers (GPs) are inorganic polymers formed by the alkaline activation of aluminosilicate materials having tetrahedral units of varying $\mathrm{Al} / \mathrm{Si}$ ratio, which may come from different industrial wastes such as metakaolin, fly ash and rice husk ash ${ }^{5}$. It has the potential to replace ordinary Portland cement due to its less carbon footprint, enhanced mechanical properties, and environment-friendliness ${ }^{6}$. Its formation involves deconstruction of the Al-Si content in the precursor due to reaction with the alkaline activator, followed by polymerization and polycondensation, forming the highly stable, semicrystalline three-dimensional cross-linked Al-Si-O species ${ }^{7}$. GPs are stable up to $13000 \mathrm{C} 6$ and resistant to wastewater photocatalytic degradation by-products ${ }^{8}$, making it a suitable support matrix for titania deposition. $\mathrm{TiO}_{2}$ is deposited on the geopolymer sphere surface using Horizontal Vapor Growth Deposition (HVPG) technique. HVPG technique has been known to produce nanocrystalline semiconductors, including organic semiconductors, because it permits milder experimental conditions that preserves the integrity of the chemical structure ${ }^{9}$. Thus, $\mathrm{TiO}_{2}$ deposited on GP surface by HVPG technique will make an environment-friendly material that is expected to have excellent photoactivity.

The goal of this study is to make a promising and economical photocatalyst material by depositing nanotitania on a GP sphere by horizontal vapor phase growth (HVPG) technique, for dye degradation in wastewater systems. The GP sphere uses MK and RHA waste materials, which serves as an eco-friendly substrate for nanotitania synthesis. HVPG technique permits nanostructured $\mathrm{TiO}_{2}$ deposition on the surface, to produce an efficient, economical material. Morphological characterization is evaluated using Scanning Electron Microscope (SEM), chemical characterization by Fourier Transform Infrared Spectroscopy (FT-IR), and elemental composition by Energy Dispersive X-Ray (EDX). The photocatalytic activity is determined in terms of methylene blue degradation, which was evaluated by UV-Vis Spectroscopy.

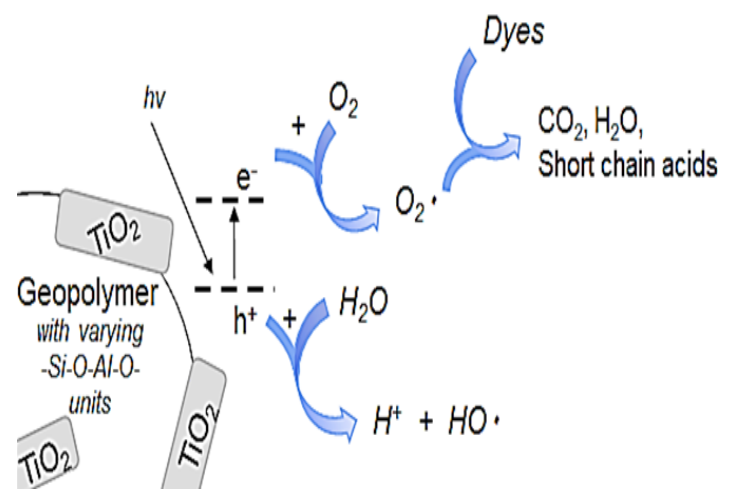

Scheme 1. Photocatalytic process in titania-deposited geopolymer sphere

\section{MATERIALS AND METHODS}

\section{Materials}

Metakaolin (MK) and rice hull ash ( $\mathrm{RHA}$ ) were used and received from a materials recovery facility in Tarlac Province, Philippines. Sodium hydroxide $(\mathrm{NaOH})$, commercial water glass solution (WGS $_{\text {commercial }}$, modulus $=2.5 ; 34.1 \mathrm{wt} \% \mathrm{SiO}_{2}, 14.7 \%$ $\mathrm{Na}_{2} \mathrm{O}$ ), polyethylene glycol with average molecular weight of $600 \mathrm{~g} / \mathrm{mol}$ (PEG-600), polysorbate 80 and titanium (IV) oxide anatase (99.8\%) were used without further processing or purification.

\section{Synthesis of Geopolymer Spheres}

The synthesis of geopolymer spheres was done through modified procedures ${ }^{10}$. RHA (16 g, $192 \mathrm{mmol} \mathrm{SiO}_{2}$ ) and $\mathrm{NaOH}(5.33 \mathrm{~g}, 133 \mathrm{mmol})$ were suspended in $32 \mathrm{~mL}$ water, and was refluxed for $4 \mathrm{~h}$ at $90^{\circ} \mathrm{C}$. The filtered solution yielded clear homogenous water glass solution (modulus $=2.8$ ). Then, MK (16 g, $145 \mathrm{mmol} \mathrm{SiO}_{2}, 68.6 \mathrm{mmol} \mathrm{Al}_{2} \mathrm{O}_{3}$ ), polysorbate $80(0.3 \mathrm{~g})$ and distilled $\mathrm{H}_{2} \mathrm{O}(4.6 \mathrm{~g}$, $256 \mathrm{mmol}$ ) were added to $6.5 \mathrm{~g}$ prepared water glass solution $\left(\mathrm{WGS}_{\text {prep }}\right.$ ), forming an orange-brown slurry. The slurry was transferred in a $10 \mathrm{~mL}$ syringe and was dropped into PEG - 600 solution at $60^{\circ} \mathrm{C}$. Collected spheres were washed with acetone and 
cured at $75^{\circ} \mathrm{C}$ for 2 days, producing brown spheres with diameter 2-3 $\mathrm{mm}$.

\section{Titania Deposition on Geopolymer Sphere by HVPG}

Figure 1 depicts the set-up for the deposition of $\mathrm{TiO}_{2}$ on the geopolymer sphere. GP spheres, glass wool and $\mathrm{TiO}_{2}$ powder $(10 \mathrm{mg}, 0.125$ $\mathrm{mmol}$ ) were placed in a closed-end quartz tube and sealed to give an evacuated tube (pressure $=5 \times 10^{-6}$ Torr) that is sealed at both ends. An oxygen fuel torch was used to seal the tubes, while Thermionics Vacuum System was used as vacuum. The sealed tube is horizontally placed in a conventional furnace, with the spheres end protruding outside, and was baked at $1200^{\circ} \mathrm{C}$ for 6 hours.

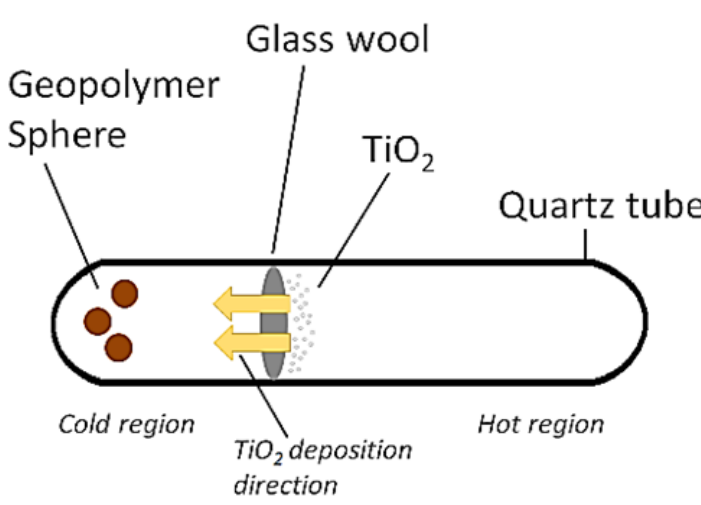

Fig. 1. Horizontal Vapor Phase Growth (HVPG) technique set-up for $\mathrm{TiO}_{2}$ deposition on geopolymer sphere

Table 1: Percent chemical composition of Metakaolin and Rice Husk Ash sourced in Tarlac Province determined by X-Ray Fluorescence (XRF) Spectroscopy.

\begin{tabular}{ccc}
\hline Oxides & Metakaolin & Rice hull ash \\
\hline $\mathrm{SiO}_{2}$ & 54.5 & 72.2 \\
$\mathrm{Al}_{2} \mathrm{O}_{3}$ & 43.7 & - \\
$\mathrm{Fe}_{2} \mathrm{O}_{3}$ & 0.8 & 8.2 \\
$\mathrm{~K}_{2} \mathrm{O}$ & 0.5 & 8.5 \\
$\mathrm{CaO}$ & 0.2 & 7.1 \\
others & 0.4 & 4.0 \\
LOI & 0.6 & 12.1 \\
\hline
\end{tabular}

\section{Materials Characterization}

The IR profile of $\mathrm{TiO}_{2}$ - deposited GP sphere was analyzed using FT-IR spectrophotometer (Nicolet Magna-IR 550) in $\mathrm{KBr}$ disk, while morphological characterization and elemental analysis were evaluated using SEM-EDX (Phenom XL 2015 LR1).

\section{Photocatalysis Experiment}

The photocatalytic experiment was carried out in triplicate using a self-made photoreactor. Initially, $\mathrm{TiO}_{2}$-deposited GP spheres were suspended in methylene blue solution in a sealed glassware, placed in a mixer and was allowed to stir for $30 \mathrm{~min}$ in the dark, to establish an absorption/desorption equilibrium. Then, the solution was illuminated with UV light for 10 hours. The UV light bulb is approximately 12 inches above the reaction mixture. The concentration of the final solution was determined by measuring its absorbance using UV-Vis spectrophotometer (Hitachi U-2900). The \% degradation was calculated as described in Equation 1.

$\%$ degradation $=\frac{/[\text { MBinit }]-[\text { MBfin }] /}{[\text { MBinit }]} \times 100 \%$

where

$\left[\mathrm{MB}_{\text {init }}\right]=$ initial $\mathrm{MB}$ concentration

$\left[\mathrm{MB}_{\text {fin }}\right]=\mathrm{MB}$ concentration after UV exposure

\section{RESULTS AND DISCUSSION}

\section{GP Sphere Synthesis}

With the aim of providing practical materials with green chemistry, RHA and MK were used as raw materials for the synthesis of geopolymer spheres. As shown in Table 1, the $72.2 \% \mathrm{SiO}_{2}$ content in $\mathrm{RHA}$ make it an ideal source of silica for the synthesis of WGS, which serves as the alkaline activator of MK. The produced geopolymer spheres had nonuniform porous structure (Fig. 2a), where no degradation and morphological changes were observed even after the deposition procedure (Fig. 2b), which makes it a suitable green substrate material for the deposition of titania.

\section{Nanostructure formation}

HVPG technique is a method capable of converting $\mathrm{TiO}_{2}$ powder into nanostructures. Vapor deposition is done in a vacuum sealed quartz or silica tube, and because of the low pressure inside the tube, even nonvolatile compounds are possible to vaporize in moderate temperatures. The set up inside the quartz tube for the $\mathrm{TiO}_{2}$ deposition on the GP sphere is shown in Fig. 1. Initially, the GP spheres and anatase $\mathrm{TiO}_{2}$ were separated using a glass wool to hold titania in place, away from the GP spheres. Upon baking, sublimed $\mathrm{TiO}_{2}$ particles travelling towards the GP spheres in the cooler region of the tube deposit on the GP surface. The dwelling time and temperature were varied to determine the optimal conditions for the nanotitania deposition. 
Results showed that nanotitania deposition is optimal at baking temperature $1200^{\circ} \mathrm{C}$ and $6 \mathrm{~h}$ dwelling time, which produced nanorod morphology that is approximately $200 \mathrm{~nm}$ wide and 1-3 $\mu \mathrm{m}$ long Figure 3 .

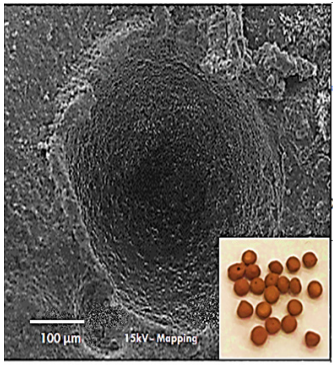

a

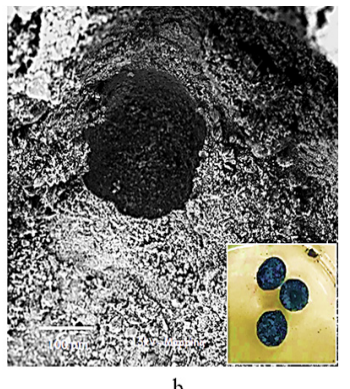

Fig. 2. SEM and actual (inset) images of geopolymer spheres (a) before and (b) after deposition

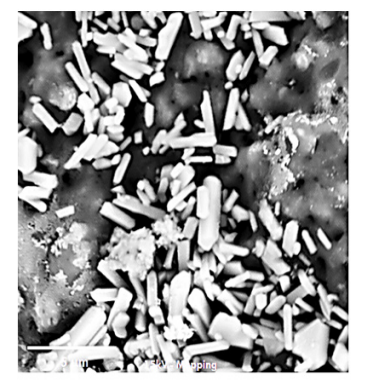

a

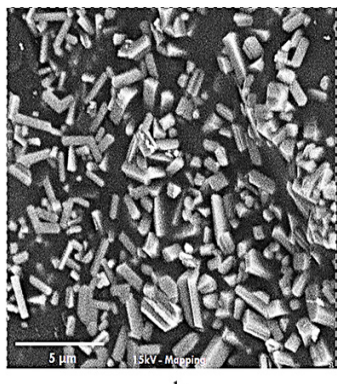

b
Fig. 3. SEM images of nanotitania (a) before and (b) after photocatalysis

The deposition of $\mathrm{TiO}_{2}$ on the geopolymer surface was further confirmed by elemental map images, which shows the presence of silicon, aluminum and titanium, as shown in Fig. 4. This was further confirmed by EDX elemental analyses, which shows approximately 2:2:1 weight percent ratio for Si:Al:Ti.

\section{Structure of $\mathrm{TiO}_{2}$-deposited GP Sphere}

The microstructure of a geopolymer matrix is composed of geopolymeric nanoparticles / micelles that gives its overall characteristic features, such as having excellent chemical and mechanical stability $^{5,6,11}$. These GP micelles initially have $\mathrm{OH}$ groups on the surface ${ }^{6}$, as illustrated on Fig. 5a, which then undergoes condensation reaction with $\mathrm{TiO}_{2}$ during HVPG process that forms a covalently linked $\mathrm{TiO}_{2}$-GP material through the formation of Ti-O-Si bond. This is confirmed by FTIR analysis of the $\mathrm{TiO}_{2}$-GP material, as shown in Fig. 6, and is compared to the GP and anatase $\mathrm{TiO}_{2}$ spectra. The bands at $\sim 1100$ and $840 \mathrm{~cm}^{-1}$ in GP are assigned to
Si-O-Si and Si-O-Al asymmetric stretching vibrations respectively ${ }^{11,12}$ where in the $\mathrm{TiO}_{2}$-GP spectra, the $840 \mathrm{~cm}^{-1}$ band is overlapped in the broad $500-800$ $\mathrm{cm}^{-1}$ peak that is assigned to Ti-O-Ti band. The 3460 and $1641 \mathrm{~cm}^{-1}$ band in GP, which is assigned to $-\mathrm{OH}$ and $\mathrm{H}-\mathrm{O}-\mathrm{H}$ stretching and bending vibrations ${ }^{12,13}$ indicates the presence of adsorbed water on the GP surface. In $\mathrm{TiO}_{2}-\mathrm{GP}$, the intensity of these peaks (1) are significantly reduced due to decreased $\mathrm{Si}-\mathrm{OH}$ species, which signifies the formation of Si-O-Ti on the GP surface and (2) are displaced towards lower wavenumber (3412 and $1632 \mathrm{~cm}^{-1}$ ) due to formation of $\mathrm{Ti}-\mathrm{O}-\mathrm{H}$ species. Furthermore, the absence of 2900, 1460 and $1352 \mathrm{~cm}^{-1}$ bands in the $\mathrm{TiO}_{2}$-GP spectra indicate elimination of the carbon groups initially present in the GP sphere. These peaks are assigned to the $\mathrm{C}-\mathrm{H}$ vibrations of unreacted $\mathrm{NaOH}$ carbonated by atmospheric $\mathrm{CO}_{2}$, which are then eliminated by the high temperature conditions in HVPG technique.
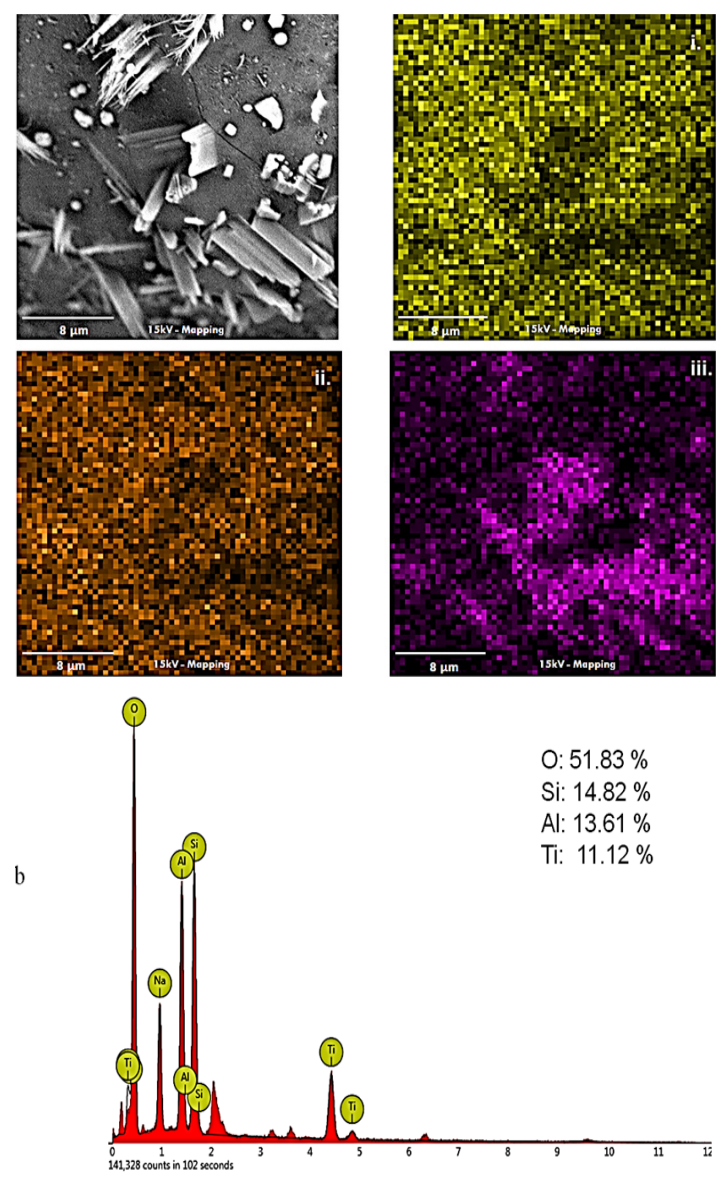

Fig. 4. (a) SEM image with (i) silicon, (ii) aluminum and (iii) titanium elemental map and (b) EDX data of $\mathrm{TiO}_{2}$-GP 


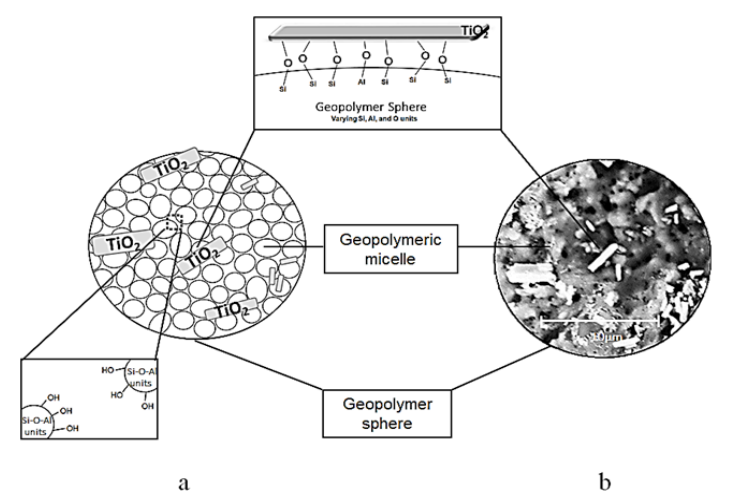

Fig. 5. (a) Illustration and (b) SEM image depicting geopolymer microstructure and the interactions present in a $\mathrm{TiO}_{2}^{-}$ deposited geopolymer sphere

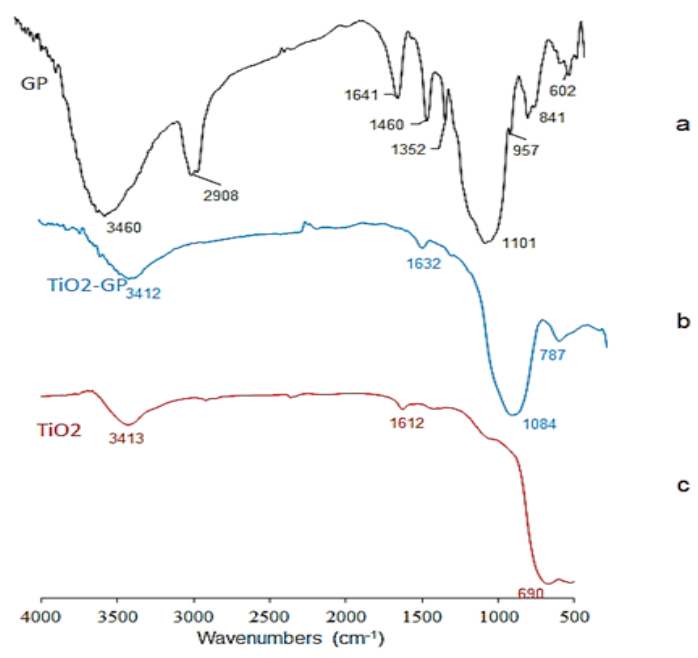

Fig. 6. FTIR Spectra of (a) geopolymer, (b) Anatase $\mathrm{TiO}_{2}$, and (c) $\mathrm{TiO}_{2}$ deposited on GP matrix

\section{Photocatalytic Activity Evaluation}

The photocatalytic activity of the synthesized $\mathrm{TiO}_{2}$-GP spheres was evaluated in terms of methylene blue degradation, where results reveal that after $10 \mathrm{~h}$ exposure, approximately 93\% methylene blue degradation was observed. This is due to the embedded nanobelt morphology of $\mathrm{TiO}_{2}$ on the GP surface provides more redox zones and greater charge mobility, resulting in reduced recombination rate, and consequently enhanced titania photoactivity.

After the photocatalysis experiment, the spheres were then subjected to SEM, elemental mapping and 3D image analyses, to check for any morphological and chemical changes. As shown in Fig. 7, SEM and elemental mapping images reveal intact $\mathrm{TiO}_{2}$ on the GP sphere surface. Further, $3 \mathrm{D}$ imaging analysis of a $\mathrm{TiO}_{2}$-GP sphere region showed $\mathrm{TiO}_{2}$ nanobelts that are embedded on the GP surface (Fig. 7c). This suggests that even after photocatalysis, no significant morphological changes were observed, thus, $\mathrm{TiO}_{2}-\mathrm{GP}$ sphere may be recycled. To check this hypothesis, the same set of $\mathrm{TiO}_{2}$-GP spheres were again tested for photocatalytic activity, employing the same conditions. The absorption spectra of methylene blue before and after exposures is shown in Figure 8 , revealing similar methylene blue degradation (approximately 91\%) even after second exposure.

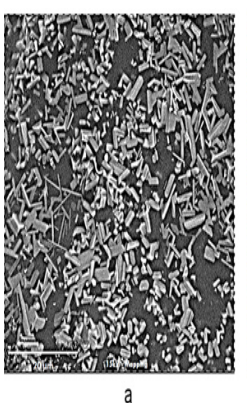

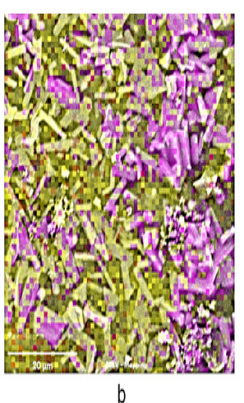

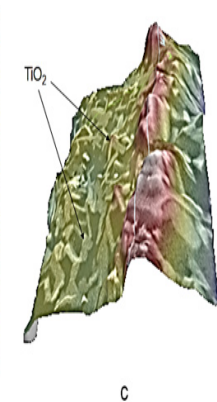

Fig. 7. (a) SEM, (b) elemental mapping ${ }^{*}$, and (c) 3D image of $\mathrm{TiO}_{2}$-GP after photocatalysis. ${ }^{*}$ pink $=\mathrm{Ti}$; yellow $=\mathrm{Al}$, $\mathrm{Si}$ and $\mathrm{O}$

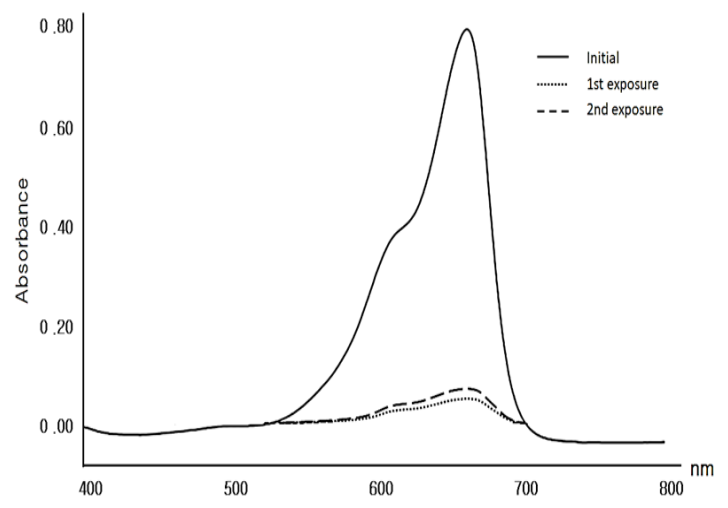

Fig. 8. Absorption spectra of methylene blue solution before and after the first and second exposures to $\mathrm{TiO}_{2}^{-}$ deposited GP spheres

\section{CONCLUSION}

The geopolymer sphere synthesized from recycled materials (i.e. metakaolin, which served as the aluminosilicate source, and rice hull ash, as the silicate source of the activating solution) were shown to be promising catalyst support matrix for nanotitania deposition. Titania was deposited via a 
modified horizontal vapor phase growth technique, producing an efficient photocatalyst for pollutant degradation. Approximately $90 \%$ degradation was reported, which was shown to give similar results when the geopolymer photocatalysts were reused. Thus, the synthesis of $\mathrm{TiO}_{2}$-deposited geopolymer sphere is an efficient, economical and sustainable material that may be utilized in photocatalytic degradation of dye pollutants in wastewater.

\section{ACKNOWLEDGEMENT}

The authors are grateful for the financial support from the University Research Coordination Office (URCO) of De La Salle University.

\section{REFERENCES}

1. Deng, Y.; Renzun, Z. Curr. Pollut. Reports., 2015, 1, 167-176.

2. Jain, A.; Vaya, D. J. Chil. Chem. Soc., 2017, 62, 3683-3690.

3. Wu, N.; Wang, J.; De Nyago, T.; Wang, H.; Zheng, J-G.; Lewis, J.P.; Liu, X.; Leonard, S.S.; Manivannan, A. J. Am. Chem. Soc., 2010, 132, 6679-6685.

4. Lazar, M.A.; Varghese, S.; Nair, S. S. Catalysts., 2012, 2, 572-601.

5. Davidovits, J. J. Therm. Anal., 1991, 37, 1633-1656.

6. Davidovits, J. J. Ceram. Sci. Technol., 2017, 8, 335-350.

7. Yao, X.; Zhang, Z.; Zhu, H.; Chen, Y.
Thermochim. Acta., 2009, 493, 49-54.

8. Bakharev, T. Cem. Concr. Res., 2005, 35, 658-670.

9. Shimizu, E.; Santos, G.N.; Yu, D.E. J. Nanotechnol., 2016, 517, 5462.

10. Tang, Q.; Ge, Y.; Wang, K.; He, Y.; Cui, X. J. Mater. Des., 2015, 88, 1244-1249.

11. Schmucker, M.; MacKenzie, K. J. D. Ceram. Int., 2005, 31, 433-437.

12. Barbosa, V.F.F.; MacKenzie, K.J.D.; Thaumaturgo, C. Int. J. Inorg. Mater., 2000, 2, 309-317.

13. Pinho, L.; Mosquera, M.J. J. Phys. Chem. C., 2011, 115, 22851-22862. 